\title{
Restructuring of gold-palladium alloyed nanoparticles: a step towards more active catalysts for oxidation of alcohols
}

\author{
Tiago A. G. Silva, ${ }^{[a]}$ Camila P. Ferraz, ${ }^{[a]}$ Renato V. Gonçalves, ${ }^{[b]}$ Erico Teixeira-Neto, ${ }^{[c]}$ Robert \\ Wojcieszak, ${ }^{[d]}$ Liane M. Rossi ${ }^{*[a]}$
}

Abstract: AuPd alloyed nanoparticles are regarded as very active catalysts for oxidation of alcohols. However we found that their catalytic activity can be further improved after calcination in air, which lead to the restructuring of alloyed AuPd nanoparticles and $\mathrm{PdO}$ segregation on the surface. The alloyed character was partially recovered upon reduction with $\mathrm{H}_{2}$ atmosphere, but the yet Pd-rich surface was less active in the oxidation of the model molecule benzyl alcohol.

\section{Introduction}

Bimetallic nanoparticles have received increasing attention in catalysis due to synergistic effects and the possibility of tuning the activity by changing the metal-to-metal relative composition. ${ }^{1,2}$ However, the structural complexity of bimetallic catalysts is high, they can restructure during pre-treatment steps and under reaction conditions, assuming different metal domains distributions and chemical state..$^{3-9}$

In the colloidal synthetic route, also known as the solimmobilization method, the nanoparticle synthesis and the deposition on the support are separated into two subsequent steps allowing the well-controlled properties of bimetallic nanoparticles (uniform size, controllable morphology and tunable composition) to be transferred to the supported catalyst. This control is difficult to achieve following the impregnation-reduction or deposition synthetic approaches. ${ }^{10,11}$ The colloidal synthetic route has been used for the preparation of gold bimetallic catalysts for some time, ${ }^{12-20}$ but a more complete characterization of the bimetallic nanoparticle surface, metal domain distribution, their chemical state and all possible restructuring processes after thermal treatments has been overlooked.

Gold-Palladium nanoparticle (NP) catalysts exhibit remarkable activity in both aqueous-phase and solventless oxidation of alcohols and olefins, ${ }^{21-25}$ direct synthesis of hydrogen peroxide, ${ }^{26}$

[a] Prof. Dr.L. M. Rossi, T. A. G. Silva, C. P. Ferraz,

Departamento de Química Fundamental, Instituto de Química, Universidade de São Paulo, Av. Prof. Lineu Prestes 748, São Paulo, 05508-000, SP (Brazil). Irossi@iq.usp.br

[b] Prof. Dr. R. V. Goncalves Instituto de Física de São Carlos, Universidade de São Paulo, CP 369, 13560-970 São Carlos, São Paulo Brazil

[c] Dr. E. Teixeira-Neto

Laboratório de Microscopia Eletrônica, LNNano-CNPEM, C.P. 6192 , 13083-970, Campinas, SP, Brazil.

[d] Dr. R. Wojcieszak

Univ. Lille, CNRS, Centrale Lille, ENSCL, Univ. Artois, UMR 8181 UCCS - Unité de Catalyse et Chimie du Solide, F-59000 Lille,

France

Supporting information for this article is given via a link at the end of the document. vinyl acetate production, ${ }^{27}$ carbon monoxide oxidation, ${ }^{28,29}$ and toluene oxidation. ${ }^{30}$ Prati and Rossi ${ }^{31}$ and Corma and Garcia ${ }^{32}$ showed that supported Au NPs are very selective catalysts for oxidation of alcohols, and good conversion was achieved in the presence of base or due to the support. Hucthings et al. ${ }^{21}$ showed that the addition of palladium to form Au-Pd alloy NPs leads to an enhancement in activity by a factor of ca. 27 compared with the monometallic gold and palladium NP catalysts, while the aldehyde is also formed with very high selectivities. Composition effect was also reported, where a progressive increase in catalytic activity was observed on increasing the Pd content, with the optimum ratio of $\mathrm{Au}: \mathrm{Pd}$ in ca. $1: 1.85$, and a progressive decrease of activity with further increase in the Pd content. ${ }^{33}$ The AuPd NPs were dried at 120 ${ }^{\circ} \mathrm{C}$ for $16 \mathrm{~h}$ and the experimental surface $\mathrm{Pd} / \mathrm{Au}$ molar ratios were obtained by $X$ ray photoelectron spectroscopy (XPS). A more detailed study of the effect of thermal treatment $(120,200$, 300 and $400{ }^{\circ} \mathrm{C}$ ) on the surface composition and catalytic activity was also reported for the sample of 1:1.85 Au:Pd molar ratio. ${ }^{34}$ From the XPS data, Au was reduced, whereas the oxidation state of $\mathrm{Pd}$ progressively changes from $\mathrm{Pd}^{0}$ to $\mathrm{Pd}^{2+}$ with the increase of calcination temperature. The authors concluded that there should be an optimum ratio between $\mathrm{Pd}^{0}-\mathrm{Pd}^{2+}$ species that will maintain a high activity as well as high selectivity to hydrogen peroxide. The catalytic activity of AuPd NPs in the oxidation of $\mathrm{CO}$ is also affected significantly by the different pretreatment conditions. Oxidation induces dealloying and enrichment of $\mathrm{PdO}$ on the surface but has a negative effect on activity, while $\mathrm{H}_{2}$ reduction results in realloying with just slight surface enrichment of $\mathrm{Pd}$ and a much higher activity. ${ }^{35}$ Understanding of structure and composition of AuPd NP catalysts after pre-treatment under reaction conditions is the key principle for design a more active catalyst and to find robust structure-activity relationships. XPS coupled with $X$ ray absorption spectroscopy (XAS) analysis are strong tools for investigating the surface and bulk compositions of the studied nanoparticles. The extent of alloying, $J,{ }^{36}$ which consists of a comparison of the EXAFS-determined coordination numbers and the expected coordination numbers in an ideal alloy is powerful for characterising the structure of a bimetallic nanostructure.

Here we investigated the structural properties of freshlyprepared (untreated) and thermally treated silica-supported AuPd NPs under air and then reduced in hydrogen atmosphere (Scheme 1); as a probe to surface activity of bimetallic AuPd NPs were tested in the oxidation of benzyl alcohol. 


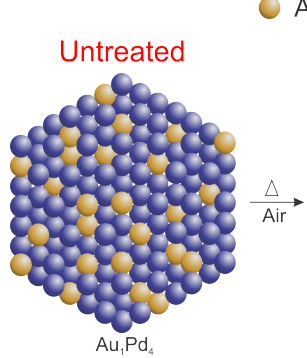

$\mathrm{Au} \odot \mathrm{Au}^{3+} \odot \mathrm{Pd} \odot \mathrm{Pd}^{2}$
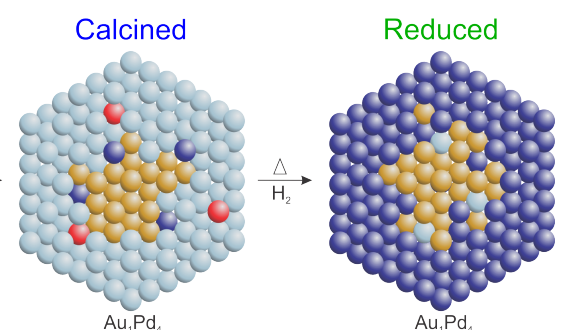

Scheme 1. Schematic cross-sectional representation of freshly-prepared alloyed AuPd4 NPs, and proposed structures after calcination in air and after reduction with molecular hydrogen.

\section{Results and Discussion}

AuPd NPs with composition of Au:Pd 1:4 were prepared by the colloidal synthesis route and supported on silica-coated magnetite nanoparticles, a support that facilitates the catalyst separation and recovery. The metal loading measured by F-AAS was close to $1 \mathrm{wt} \%(0.23 \mathrm{wt} \% \mathrm{Au}, 0.50 \mathrm{wt} \% \mathrm{Pd}$, and atomic ratio $\mathrm{Au}: \mathrm{Pd} 1: 4)$. The freshly-prepared catalyst was dried at $100^{\circ} \mathrm{C}$ and other samples were obtained after calcining the catalyst at $500^{\circ} \mathrm{C}$ for $2 \mathrm{~h}$ in air. The samples were analyzed by TEM and STEM in order to determine the AuPd NP average particle size. The mean size of the untreated bimetallic nanoparticles $(4.6 \pm$ $2.1 \mathrm{~nm})$ increased only $1 \mathrm{~nm}$ after calcination $(5.5 \pm 1.5 \mathrm{~nm})$ (Figure 1). However, size-composition diagrams, obtained by EDS analysis of individual nanoparticles, revealed a broadening of the nanoparticle composition after calcination, suggesting metal segregation upon heating (Figure 2). The nominal molar composition for $\mathrm{Au}$ in AuPd alloyed NP is $20 \% \mathrm{Au}$, but the composition of individual particles measured by EDS ranged from 10 to $25 \% \mathrm{Au}$, in the untreated sample, and 0 to $55 \% \mathrm{Au}$, in the calcined sample. The changes in the sample after calcination were better investigated by XPS, XRD and XAS (Note: In order to better characterize the prepared catalysts by solid-state techniques, we prepared mimetic catalysts, comprised by a non-magnetic silica support, with a metal loading of $6 \%(A u+P d))$.

The surface-composition determined by XPS shown in Figure 3 revealed an increase in surface-Pd after calcination under air, which suggests the restructuring of the AuPd alloy and $\mathrm{Pd}$ segregation to the surface (Table 1, see SI Table S1 and S2). The trend in the relative percentages of $\mathrm{Pd}$ and $\mathrm{Au}$ revealed important differences in the interaction between these two metals after thermal treatment. The untreated catalyst has the chemical composition close to the nominal ( $\mathrm{Pd}$ :Au atomic ratio of 4). After calcination, the $\mathrm{Au}$ surface content decreased significantly (from $0.8 \%$ to $0.39 \%$ ) and the $\mathrm{Pd} / \mathrm{Au}$ ratio increased from 3.5 to 7.9. Along with the increase in surface $\mathrm{Pd}$ after calcination, the oxidation of $\mathrm{Pd}$ to $\mathrm{Pd}^{2+}$ species is a strong evidence of AuPd nanoparticles dealloying and of Pd migration to the surface. A small amount of $\mathrm{Au}^{3+}$ species $(0.12 \%)$ was detected (the Au4f doublet had a $3.67 \mathrm{eV}$ separation between the $A u 4 f_{7 / 2}$ and $A u 4 f_{5 / 2}$ peaks, and a new doublet presenting a $3.20 \mathrm{eV}$ shift from the $\mathrm{Au}^{0}$ doublet was observed (Figure S1 and Table S1)). Since most of the Pd segregated on the surface is oxidized, and only a few gold atoms are located on the surface after calcination, we may not exclude the presence of single $\mathrm{Au}$ atoms trapped in the PdO lattice. When the calcined sample was reduced with $\mathrm{H}_{2}$, the $\mathrm{Pd} / \mathrm{Au}$ ratio decreased to 6.3 (Table 1). Indeed, the Au content on the surface increased, suggesting $\mathrm{Au}$ migration to the surface and some level of reconstruction of the alloy-like structure. The binding energies of $\mathrm{Au}^{0} 4 \mathrm{f}\left(4 \mathrm{f}_{7 / 2}=83.33\right.$ $\mathrm{eV})$ and $\mathrm{Pd}^{0} 3 \mathrm{~d}\left(3 \mathrm{~d}_{5 / 2}=334.92 \mathrm{eV}\right)$ are slightly different from the values observed for $\mathrm{Au}^{0}\left(4 \mathrm{f}_{7 / 2}=82.98 \mathrm{eV}\right)$ and $\mathrm{Pd}^{0}\left(3 \mathrm{~d}_{5 / 2}=\right.$ $334.87 \mathrm{eV}$ ) in the untreated sample (Table S1).
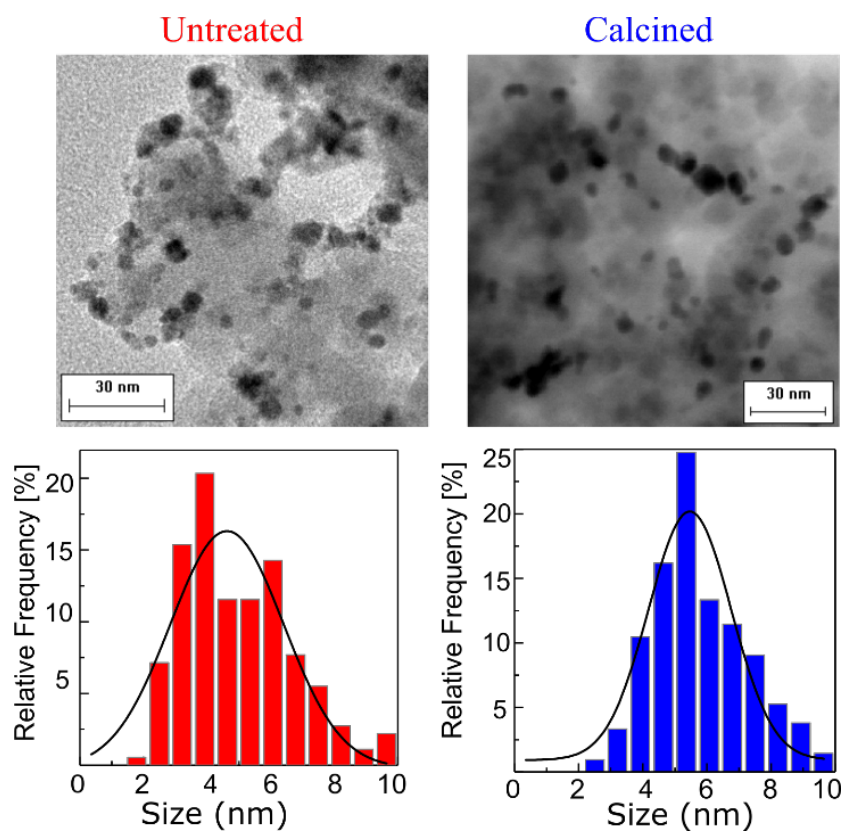

Figure 1. TEM analysis of the untreated and STEM analysis of the calcined catalyst samples and size distribution histograms.

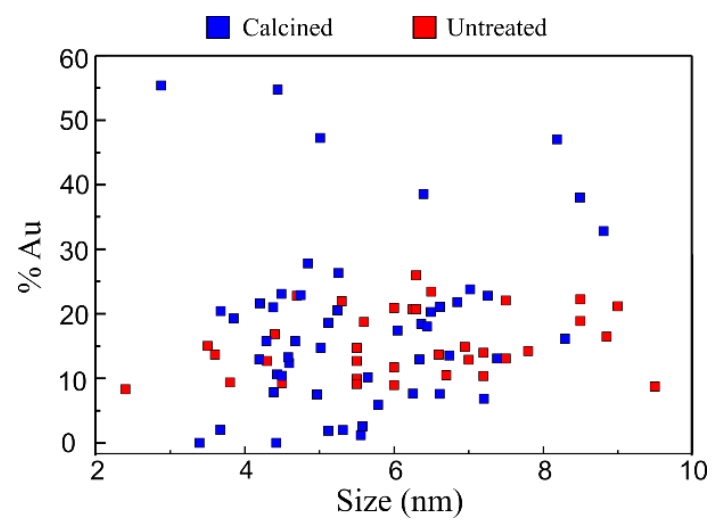

Figure 2. Size-composition diagrams obtained by EDS analysis of the catalyst samples. Number of individual particles analysed: 50 untreated and 50 calcined samples.

These differences of energy peak locations are due to the electronic interactions between the $\mathrm{Pd}$ and $\mathrm{Au}$ after thermal treatment. Moreover, the freshly-prepared and calcined samples have comparable metal content (Au+Pd) of about $3.5 \%$. Contrary, the reduced sample has only $1.2 \%$ of the metals on the surface. This is probably due to a significant increase in particle size after reduction (Figure 4). 


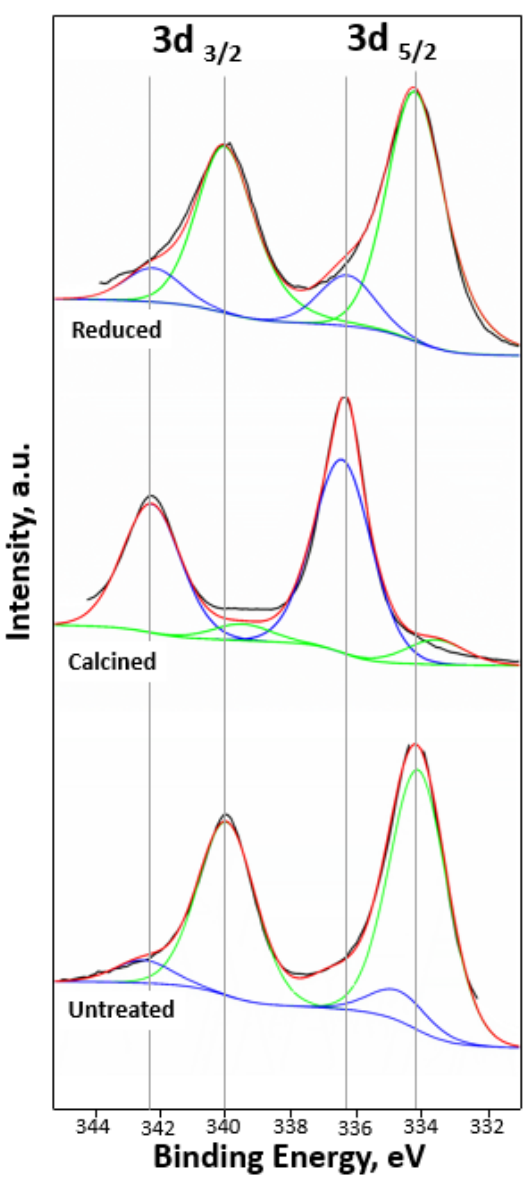

Figure 3. XPS Pd 3d region for untreated, calcined and reduced (after calcination) catalyst samples.

Table 1. XPS analysis of the AuPd $1: 4$ catalysts. Au and Pd atomic $\%$ and $\mathrm{Pd} / \mathrm{Au}, \mathrm{Pd} / \mathrm{Si}$ and $\mathrm{Au} / \mathrm{Si}$ atomic ratios.

\begin{tabular}{cccccccc}
\hline Catalyst & & \multicolumn{2}{c}{$\mathrm{Au}+\mathrm{Pd}(\%)$} & & $\mathrm{Pd} / \mathrm{Au}$ & $\mathrm{Pd} / \mathrm{Si}$ & $\mathrm{Au} / \mathrm{Si}$ \\
& $\mathbf{P d}^{0}$ & $\mathbf{P d}^{2+}$ & $\mathbf{A u}^{\mathbf{0}}$ & $\mathbf{A u}^{3+}$ & & & \\
\hline Untreated & 2.47 & 0.31 & 0.68 & 0.12 & 3.5 & 0.10 & 0.03 \\
Calcined & 0.35 & 2.77 & 0.35 & 0.04 & 7.9 & 0.10 & 0.01 \\
Reduced & 0.85 & 0.17 & 0.16 & - & 6.3 & 0.03 & 0.004 \\
\hline
\end{tabular}
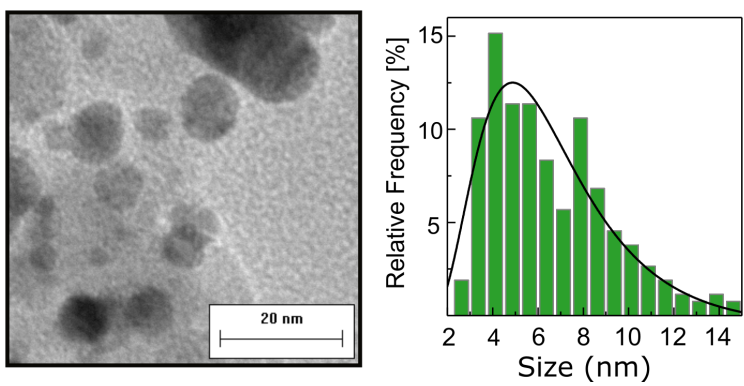

Figure 4. TEM analysis of the $\mathrm{H}_{2}$-treated catalyst after calcination (reduced)

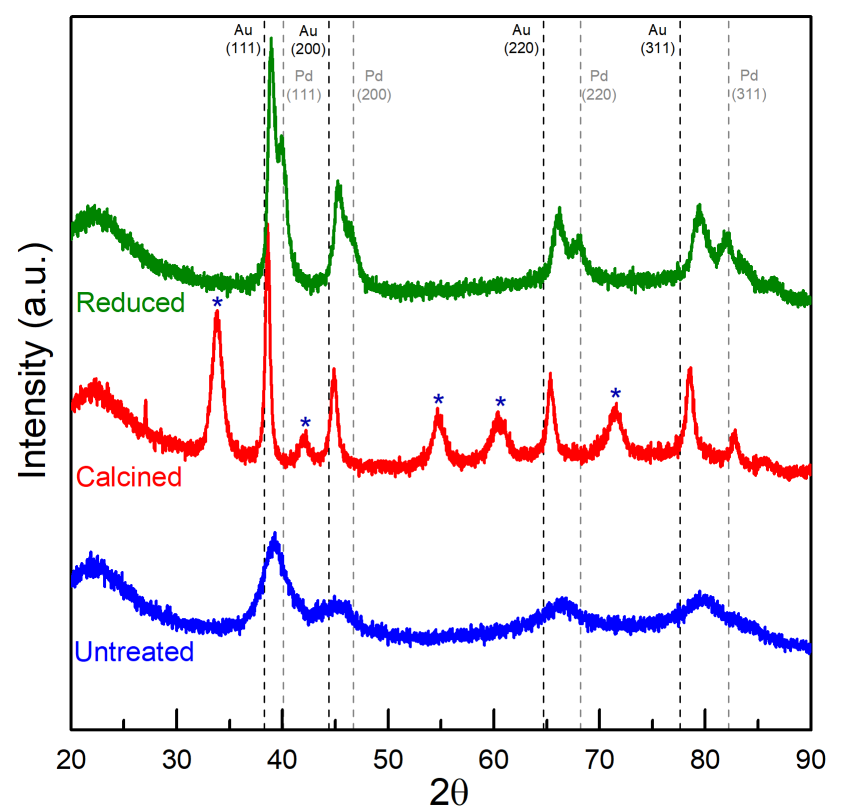

Figure 5. XRD pattern of the AuPd 1:4 catalysts: untreated, calcined and reduced after calcination. $\mathrm{PdO}$ phase is indicated by star markers.

The XRD patterns obtained for the freshly-prepared, calcined and reduced (after calcination) catalyst samples are fully consistent with the XPS results (Figure 5). The XRD pattern of the untreated sample corresponds to the diffraction peaks of an alloyed AuPd crystalline phase. The diffraction peak for the (111) plane is in the middle way between $\mathrm{Au}$ (111) and $\mathrm{Pd}$ (111) peaks, which correspond to diffraction peak of AuPd metal alloy according to Vegard's law. The peak position at $2 \theta=39.30$ is however shifted from the expected value of $2 \theta=39.76$ for $\mathrm{Au}_{1} \mathrm{Pd}_{4}$, suggesting a bulk composition of $\mathrm{Au}_{1} \mathrm{Pd}_{1.3}{ }^{37,38}$ After sample calcination, the emergence of a new PdO crystal phase is clear, while the diffraction peak for the (111) plane is now shifted towards the $\mathrm{Au}$ (111) peak, with a bulk composition of $\mathrm{Au}_{4} \mathrm{Pd}_{1}$. From $\mathrm{XRD}$, it is evident that segregation and oxidation of $\mathrm{Pd}$ occurred after calcination. Interestingly, when the calcined sample was reduced with $\mathrm{H}_{2}$, the diffraction peak for the (111) plane split into two components, the first component is slightly shifted to higher $2 \theta$ values suggesting the alloy is partially restored, to a bulk composition of $\mathrm{Au}_{1.7} \mathrm{Pd}_{1}$. The second peak is difficult to assign as it can be either $\mathrm{Pd}(111)$ or partially restored AuPd(111) alloy and Vegard law suggests a bulk composition of $\mathrm{Au}_{1} \mathrm{Pd}_{7.3}$. The presence of a rich palladium phase suggests that segregation of palladium to the surface is not reversible, and $\mathrm{Au}$ did not completely redissolve in the Pd phase (see SI Figure S2 and Table S3). The diffraction peaks of (220) and (311) planes are shifted with respect to pure Au crystal phase, which may give evidence of at least a partial reconstruction of the AuPd alloy phase.

The samples were analysed by XAS (see S.I. for a detailed analysis of the XAFS data). Figure 6 displays the $A u L_{3}$-edge and Pd K-edge Fourier transformed (FT) EXAFS $k^{3} x(k)$ curves of the freshly-prepared, calcined and reduced (after calcination) AuPd catalyst samples. The Au $\mathrm{L}_{3}$-edge FT curves show peaks in the 2-3 $\AA$ region formed by the contribution of $\mathrm{Au}-\mathrm{Au}$ and $\mathrm{Au}-$ 
Pd scattering paths that are slightly out of phase. The peak shape and position were changed with the thermal treatment conditions. These changes are related to evolution of the composition of the alloyed phases, creating two peaks in the real part of the Fourier-transformed EXAFS curve. Furthermore, the $\mathrm{Pd}$ K-edge also shows a peak in the 2-3 $\AA$ region, but the calcined sample reveals an additional peak between 1.2-1.8 $\AA$ from the scattering path $\mathrm{Pd}-\mathrm{O}$.

Table 2. Calculated EXAFS coordination numbers and atomic distances. Extent of alloying $J$ determined by the EXAFS-obtained coordination numbers and corrected by the F-AAS-determined compositions.

\begin{tabular}{|c|c|c|c|c|c|c|c|c|c|c|c|}
\hline \multirow{2}{*}{ Sample } & \multicolumn{4}{|c|}{ Au $L_{3}$-Edge } & \multicolumn{5}{|c|}{ Pd K-Edge } & \multicolumn{2}{|l|}{$J$} \\
\hline & $\mathrm{Au}-\mathrm{Au}$ & $\mathrm{R}(\AA)$ & $\mathrm{Au}-\mathrm{Pd}$ & $\mathrm{R}(\AA)$ & $\mathrm{Pd}-\mathrm{Pd}$ & $\mathrm{R}(\AA)$ & $\mathrm{Pd}-\mathrm{Au}$ & $\mathrm{R}(\AA)$ & $\mathrm{Pd}-\mathrm{PdO}$ & $\mathrm{Au}$ & $\mathrm{Pd}$ \\
\hline Untreated & $2.7 \pm 0.3$ & $2.800 \pm 0.01$ & $7.2 \pm 0.5$ & $2.785 \pm 0.005$ & $7 \pm 1$ & $2.780 \pm 0.01$ & $3.1 \pm 0.9$ & $2.77 \pm 0.03$ & - & 107 & 96 \\
\hline Calcined & $7.9 \pm 0.6$ & $2.842 \pm 0.005$ & $2.0 \pm 0.3$ & $2.830 \pm 0.01$ & - & - & - & - & $3.7 \pm 0.3^{a}$ & 28 & 0 \\
\hline Reduced & $5.0 \pm 0.4$ & $2.820 \pm 0.006$ & $5.5 \pm 0.4$ & $2.798 \pm 0.005$ & $9.8 \pm 0.8$ & $2.739 \pm 0.004$ & $1.3 \pm 0.5$ & $2.75 \pm 0.04$ & $0.6 \pm 0.3^{b}$ & 72 & 48 \\
\hline
\end{tabular}

${ }^{\mathrm{a}} \mathrm{R}=3.036 \pm 0.002 \AA .{ }^{\mathrm{b}} \mathrm{R}=3.02 \pm 0.04 \AA$

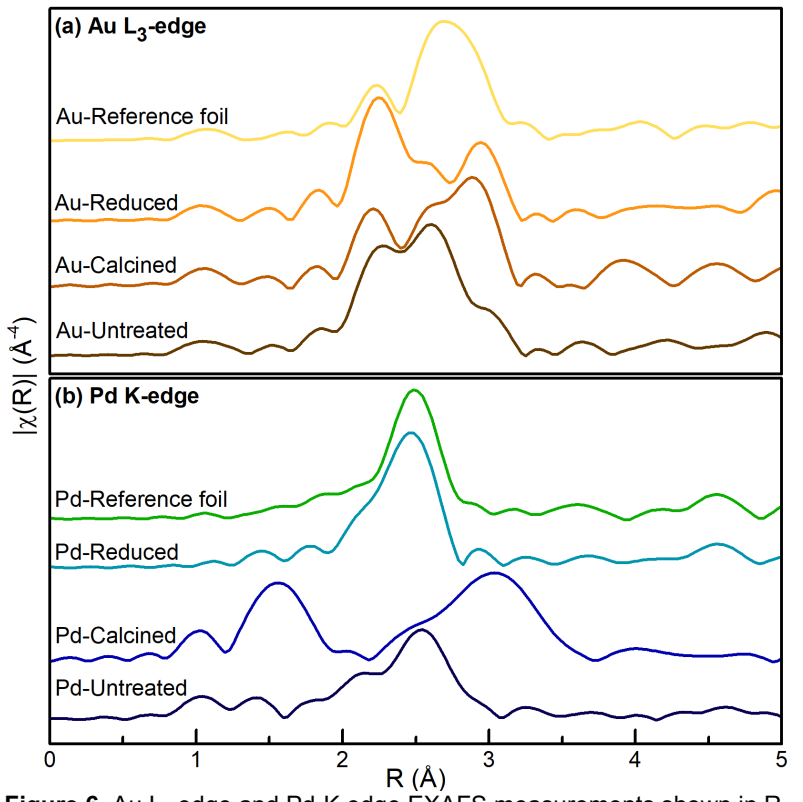

Figure 6. Au $L_{3}$ edge and $\mathrm{Pd}-\mathrm{K}$ edge EXAFS measurements shown in Rspace $\left(\mathrm{k}^{3}\right)$ for the untreated, calcined and reduced catalyst samples.

The absence of this peak after sample reduction discloses that the metallic character of the sample can be recovered, but the increase in intensity of the peak in the 2-3 $\AA$ region discloses additional Au-Pd segregation after reduction. These observations can be further explained by EXAFS fitting. Table 2 shows the evolution of the EXAFS-calculated coordination numbers on the $\mathrm{Au} \mathrm{L}_{3}$ edge and $\mathrm{Pd} \mathrm{K}$-edge, characterizing the formation of a random alloy for the untreated sample, close to the ideal structure with prevailing heteroatomic interactions, as evidenced by calculating the extent of alloying $J$ (Table 2$).{ }^{12}$ The value of $\mathrm{J}$ calculated for $\mathrm{Au}$ is slightly superior to 100 for the untreated sample, suggesting a greater affinity for heteroatom bonding. The values of $\mathrm{J}$ are, however, very close to 100 for both $\mathrm{Au}$ and $\mathrm{Pd}$, and suggest the formation of a random alloy. After calcination, metal segregation occurred in the form of $\mathrm{Au}$ and $\mathrm{PdO}$, as observed by $\mathrm{XRD}$. Although Au-Pd interaction could be determined in the Au L3-edge EXAFS, only PdO was observed from the Pd K-edge EXAFS, without interactions with $\mathrm{Au}$ atoms. The calcined sample was then reduced with $\mathrm{H}_{2}$ and most of the PdO was reduced to metallic Pd (Figure 6) and the alloy was partially restored ( $\mathrm{J}$ of $48 \%$ for Au L3-edge and $72 \%$ for $\mathrm{Pd}$ k-edge). These values of $J$, lower than $100 \%$, suggest that even though bimetallic character is recovered, homoatomic interactions are dominant and the sample consists of an Au-rich alloy and another Pd-phase. These observations can be further supported by the comparison of the FT EXAFS curves, shown in

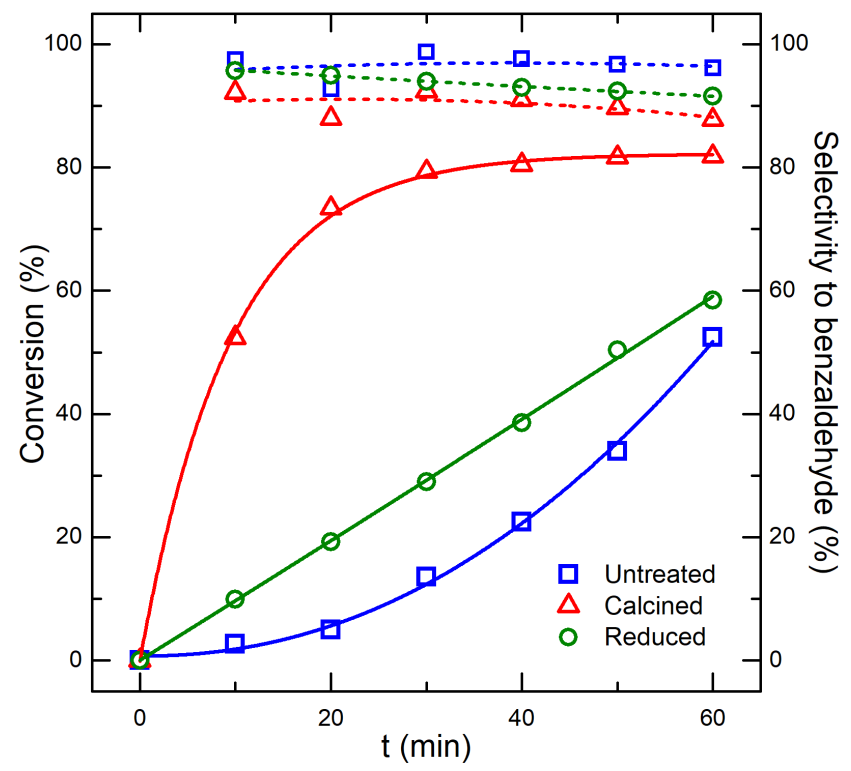

Figure 7. Benzyl alcohol conversion kinetics for the freshly-prepared catalyst (untreated, open squares), calcined catalyst (open triangles) and $\mathrm{H}_{2}$-treated catalyst after calcination (reduced, open circle). Dashed lines indicate selectivity (\%) to benzaldehyde. Other minor products formed are benzyl benzoate and benzoic acid. The calcined sample also formed $0.9 \%$ of toluene. Reaction conditions: $0.75 \mathrm{mg} \mathrm{Au}+\mathrm{Pd}, 9.6 \mathrm{mmol}$ benzyl alcohol, $373.15 \mathrm{~K}, 6$ bar $\mathrm{O}_{2}$.

R-space $\left(k^{3}\right)$, once the $A u L_{3}$-edge curve is dissimilar to the $A u$ reference foil and the $\mathrm{Pd} \mathrm{K}$-edge curve shows a similar form to that of the Pd foil.

Since AuPd alloyed nanoparticles receive so much attention as catalysts for the selective oxidation of alcohols, ${ }^{12-25}$ we decided to study any possible effect of surface changes that occurred upon thermal treatment in oxidizing and reducing atmospheres on the reaction rates of benzyl alcohol oxidation (Figure 7). The AuPd nanoparticles after calcination, i.e. the catalysts with PdO phase, were found to be more active than the freshly-prepared AuPd alloyed NPs for liquid-phase benzyl alcohol oxidation, while the high selectivity for benzaldehyde was preserved. Besides the positive effect expected of cleaning the surfaces from the capping agents, the segregation of palladium and its oxidation seems to play a major role in the catalytic activity. Contrarily, the $\mathrm{H}_{2}$-treated sample; i.e. $\mathrm{PdO}$ was converted to 
metallic Pd, showed a drastic drop in activity. Lee et al. ${ }^{39}$ found a direct correlation between the presence of $\mathrm{PdO}_{x}$ surface sites and the reactivity in selective oxidation of alcohols over monometallic Pd catalysts. They also showed that reduction of $\mathrm{PdO}_{\mathrm{x}}$ to $\mathrm{Pd}$ metal suppresses activity, and that catalyst prereduction likewise dramatically impairs oxidation. ${ }^{40}$ The performance of AuPd NP catalysts has mostly been attributed to nanoalloys that can be formed at any $\mathrm{Au}$ and $\mathrm{Pd}$ ratios, but the contribution of PdO to improve the activity of bimetallic AuPd NP catalysts has been neglected.

\section{Conclusions}

Bimetallic AuPd NPs were first prepared and then immobilized on the support in order to preserve the properties obtained in the colloidal synthesis (size and composition). However, the combination of techniques has allowed us to follow the restructuring of these bimetallic NPs after thermal treatment in air and then after reduction with $\mathrm{H}_{2}$ (Scheme 1). The asprepared alloyed nanoparticles have restructured into AuPd/PdO after segregation of palladium and oxidation the surface. The $\mathrm{Au}$ rich core-PdO rich shell became much more active for the oxidation of benzyl alcohol than the homogeneous alloy. We believe the remarkable effect of restructuring and dealloying should not be neglected due to a significant change in the catalytic activity. Metal segregation under reaction conditions has also to be taken into account in the study of other gold bimetallic catalysts. The effect of thermal treatments in AuPd alloys of different compositions is under study in our group.

\section{Experimental Section}

\section{Synthesis of supported AuPd nanoparticles.}

Gold and palladium monometallic and bimetallic nanoparticles of desired composition were synthesized by mixing a solution of $\mathrm{HAuCl}_{4}(3.31 \mathrm{~mL}$, $\left.4.85 \times 10^{-3} \mathrm{~mol} \mathrm{~L}^{-1}\right), \mathrm{PdCl}_{2}\left(2.85 \mathrm{~mL}, 2.25 \times 10^{-2} \mathrm{~mol} \mathrm{~L}^{-1}\right)$ and polyvinyl alcohol (PVA) $(1.2 \mathrm{~mL}, 1 \% \mathrm{~m} / \mathrm{v})$ and reducing with $\mathrm{NaBH}_{4}(4.02 \mathrm{~mL}, 0.1$ $\mathrm{mol} \mathrm{L^{-1 }}$ ). After mixing the solutions were allowed to react for $30 \mathrm{~min}$ before adding a $50 \mathrm{~mL}$ aqueous suspension of $1.0 \mathrm{~g}$ of the aminofunctionalized silica-coated magnetite support $\left(\mathrm{Fe}_{3} \mathrm{O}_{4} @ \mathrm{SiO}_{2}-\mathrm{NH}_{2}\right)^{24}$ and stirring at $25{ }^{\circ} \mathrm{C}$ for $2 \mathrm{~h}$. The solid was magnetically separated and resuspended on $25 \mathrm{~mL}$ of $60{ }^{\circ} \mathrm{C}$ deionized water twice and $25 \mathrm{~mL}$ ethanol twice, and magnetically separated after each resuspension and dried under air.

Calcination and calcination-reduction post-synthesis treatment. The samples $(\sim 500 \mathrm{mg})$ were thermally treated for $2 \mathrm{~h}$ under air with a heating ramp of $20{ }^{\circ} \mathrm{C} \mathrm{min}-1$ up to $500{ }^{\circ} \mathrm{C}$. After cooling to $100{ }^{\circ} \mathrm{C}$ the samples were kept in a desiccator. A portion of calcined catalyst samples was reduced in hydrogen flow. The sample $(100 \mathrm{mg})$ was added to a quartz tube $(20 \mathrm{~cm}$ length and $5 \mathrm{~mm}$ width) filled with quartz wool. The tube was introduced in a CATLAB-PCS system (Hiden Analytical) and hydrogen with a total flow of $50 \mathrm{~mL} \mathrm{~min}{ }^{-1}$ was introduced. A heating ramp of $20{ }^{\circ} \mathrm{C} \mathrm{min}-1$ up to $500{ }^{\circ} \mathrm{C}$ was applied and the sample was left at $500{ }^{\circ} \mathrm{C}$ for $30 \mathrm{~min}$

\section{Characterization}

The total metal concentration in the catalysts was determined by FAAS on a Shimadzu AA-6300 atomic absorption spectrometer. TEM and STEM analysis were conducted using a JEOL JEM $2100 \mathrm{~F}$ microscope equipped with a FEG electron source operating at an acceleration voltage of $200 \mathrm{kV}$ (LNNano - CNPEM, Campinas, Brazil). Chemical surface composition was carried out by XPS analysis using a K-Alpha spectrometer (Thermo Scientific) at the LNNano (CNPEM, Campinas, Brazil). During the measuring, surface charging was eliminated with a double beam charge compensator. The pass energy of the analyser was held at $50 \mathrm{eV}$ for both the survey and high resolution analysis. In these conditions, the FWHM for the Au4f $\mathrm{f}_{7 / 2}$ peak was $1.5 \mathrm{eV}$. The shift of energy spectra was corrected in energy with the Si2p peak $(103.5 \mathrm{eV})$. The surface atomic concentrations were calculated by correcting the intensities with theoretical sensitivity factors based on Scofield cross sections ${ }^{41}$ and the mean free path varying according to 0.7 power of the photoelectron kinetic energy. Peak decomposition was performed using curves with a $70 \%$ Gaussian type and a $30 \%$ Lorentzian type with an asymmetric Voigt parameter for $\mathrm{Pd}$ and $\mathrm{Au}$, and a Shirley nonlinear sigmoid-type baseline. The following peaks were used for the quantitative analysis: $\mathrm{O} 1 \mathrm{~s}, \mathrm{C} 1 \mathrm{~s}, \mathrm{Si} 2 \mathrm{p}, \mathrm{Au} 4 \mathrm{f}$ and Pd 3d. Moreover, the $\mathrm{C}$ 1s peak was use to check for charge stability as a function of time. The $\mathrm{C}-(\mathrm{C}, \mathrm{H})$ component of the $\mathrm{C} 1 \mathrm{~s}$ peak of adventitious carbon was fixed to $284.8 \mathrm{eV}$ to set the binding energy scale, and the data treatment was performed using CasaXPS software (Casa Software Ltd., U.K.). X-ray powder diffraction (XRD) measurements were performed using a Ultima IVRigaku diffractometer using Cu-Ka radiation operating at $40 \mathrm{kV}$ and $30 \mathrm{~mA}$ in the 2-theta range of $20-90^{\circ}$ with a step size of $0.02^{\circ}$ and a dwell time of 5 s per step. XAFS measurements were conducted in the XAFS1 and XDS beamlines of the Brazilian Synchrotron (LNLS - CNPEM, Campinas, Brazil, proposals 16100 and 17170). Pd K edge was measured in the XDS beamline while $A u L_{3}$ edge was measured in both XAFS1 and XDS beamlines. Measurements were conducted using a Si(111) monochromator for the $\mathrm{Au} \mathrm{L}_{3}$ edge and a $\mathrm{Si}(311)$ monochromator for the $\mathrm{Pd} \mathrm{K}$ edge. Spectra analysis was conducted with the IFEFFIT library using the GUI Athena and Artemis. ${ }^{42}$ All spectra were energy calibrated to the first inflection point of the Au L3-edge and Pd K-edge at $11919 \mathrm{eV}$ and $24350 \mathrm{eV}$ respectively and normalized in Athena, using a linear preedge and a third order polynomial post-edge for background subtraction. EXAFS signal was extracted in Athena with a $R=1.0$ cut-off and $\mathrm{k}$ weight $=2$ and Fourier transformed using a Hanning window in $\mathrm{k}^{3}$ and $\mathrm{dk}=1$. EXAFS analysis was conducted in Artemis with the normalized spectra exported from Athena. The amplitude reduction factor $\left(\mathrm{S}_{0}{ }^{2}\right)$ of 0.82 for $\mathrm{Au}$ and 0.80 for Pd was obtained by fitting the EXAFS data of the respective metal foils. The simulation of scattering paths was performed with the ATOMS algorithm with a custom input file created by substituting Au atoms by $\mathrm{Pd}$ according to sample composition and calculating the cell parameters using Vegard's law. A correction factor to $\mathrm{S}_{0}{ }^{2}$ was introduced to match sample composition with F-AAS metal concentrations. Structural parameters were determined by multiple k-weight least-square fitting and the goodness of fit was determined by observing the reduced $X^{2}$ and $R^{2}$ statistical parameters.

\section{Catalytic experiments}

The oxidation reactions were performed using a modified Fischer-Porter $100 \mathrm{~mL}$ glass reactor. In a typical solventless reaction, the glass reactor was loaded with the supported AuPd-catalyst $(0.75 \mathrm{mg} \mathrm{Au}+\mathrm{Pd})$ and benzyl alcohol $(9.6 \mathrm{mmol})$. The reactor, immersed in an oil bath at $373.15 \mathrm{~K}$, was loaded with 6 bar $\mathrm{O}_{2}$. The temperature was maintained by placing the oil bath on a hot-stirring plate connected to a digital temperature controller (ETS-D5 IKA). The reactions were conducted under magnetic stirring, using Teflon-coated magnetic stir bar. At set times, the catalyst was magnetically recovered by approaching a magnet to the reactor wall, the oxygen pressure was relieved and aliquots of the reaction mixture were recovered with a syringe. The reaction products were analyzed by gas chromatography (GC) and compared to standards for the determination of conversion and selectivity using $p$-xylene as standard.

\section{Acknowledgements}


The authors are grateful to the Brazilian agencies FAPESP and $\mathrm{CNPq}$ for financial support and indebted to the Brazilian Nanotechnology National Laboratory (LNNano, Campinas, Brazil) for TEM images and XPS analysis and the Brazilian Synchrotron Light Laboratory (LNLS, Campinas, Brazil Proposals 16100 and 17170). The authors also acknowledge the INCT-Catalise.

Keywords: gold $\bullet$ palladium $\bullet$ bimetallic $\bullet$ oxidation $\bullet$ catalysis

[1] J. Xu, T. White, P. Li, C. He, J. Yu, W. Yuan and Y-F. Han, J. Am. Chem. Soc. 2010, 132, 10398-10406.

[2] J. Kaiser, W. Szczerba, H. Riesemeier, U. Reinholz, M. Radtke, M. Albrecht, Y. Lu and M. Ballauff, Faraday Discussions 2013, 162, 45-55.

[3] B-J. Hwang, L. S. Sarma, J-M. Chen, C-H. Chen, S-C. Shih, G-R. Wang, D-G. Liu, J-F. Lee and M-T. Tang, J. Am. Chem. Soc., 2005, $127,11140-11145$

[4] R. Ferrando, J. Jellinek and R. L. Johnston, Chem. Rev., 2008, 108, 845-910.

[5] G. Schimid, A. Lehnert, J-O. Malm and J-O Bovin, Angew. Chem. Int. Ed., 1991, 30, 874-876.

[6] G. Hutchings, Chem. Commun., 2008, 1148-1164.

[7] E. K. Gibson, A. M. Beale, C. R. A. Catlow, A. Chutia, D. Gianolio, A. Gould, A. Kroner, K. M. H. Mohammed, M. Perdjon, S. M. Rogers, and P. P. Wells Chem. Mater. 2015, 27, 3714-3720.

[8] P. Paalanen, B. M. Weckhuysen, and M. Sankar Catal. Sci. Technol., 2013, 3, 2869-2880.

[9] L. Delannoy, S. Giorgio, J. G. Mattei, C. R. Henry, N. E. Kolli, C. Méthivier, and C. Louis ChemCatChem 2013, 5, 2707 - 2716.

[10] K. Na, Q. Zhang and G. A. Somorjai, J. Clust. Sci., 2014, 25, 83-114.

[11] A. A. Teixeira-Neto, R. V. Gonçalves, C. B. Rodella, L. M. Rossi, E. Teixeira-Neto, Catal. Sci. Technol., 2017, 7, 1679-1689.

[12] L. Prati and G. Marta, Gold Bull., 1999, 32, 96-101.

[13] M. Comotti, W-C Li, B. Spliethoff and F. Schüth, J. Am. Chem. Soc., 2006, 128, 917-924

[14] S. Biella, L. Prati and M. Rossi, J. Catal., 2003, 206, 242-247.

[15] J.-D. Grunwaldt, C. Kiener, C. Wögerbauer and A. Baiker, J. Catal., 1999, 181, 223-232.

[16] J. Pritchard, M. Piccinini, R. Tiruvalam, Q. He, N. Dimitratos, J. A. Lopez-Sanchez, D. J. Morgan, A. F. Carley, J. K. Edwards, C. J. Kielyb and G. J. Hutchings, Catal. Sci. Technol., 2013, 3, 308-317.

[17] W. C. Ketchie, M. Murayama and R. J. Davis, J. Catal. 2007, 250, 264-273.

[18] N. Dimitratos, J. A. Lopez-Sanchez, D. Morgan, A. F. Carley, R. Tiruvalam, C. J. Kiely, D. Bethell and G. J. Hutchings, Phys. Chem. Chem. Phys., 2009, 11, 5142-5153.

[19] J. Pritchard, L. Kesavan, M. Piccinini, Q. He, R. Tiruvalam, N. Dimitratos, J. A. Lopez-Sanchez, A. F. Carley, J. K. Edwards, C. J. Kiely and G. J. Hutchings, Langmuir, 2010, 26, 16568-16577.

[20] J. A. Lopez-Sanchez, N. Dimitratos, N. Glanville, L. Kesavan, C. Hammond, J. K. Edwards, A. F. Carley, C. J. Kiely and G. J. Hutchings, Appl. Catal., A, 2011, 391, 400-406.
[21] D. I. Enache, J. K. Edwards, P. Landon, B. Solsona-Espriu, A. F. Carley, A. A. Herzing, M. Watanabe, C. J. Kiely, D. W. Knight and G. J. Hutchings, Science, 2006, 311, 362-365.

[22] N. Dimitratos, A. Villa, D. Wang, F. Porta, D. Su and L. Prati, J. Catal., 2006, 244, 113-121.

[23] L. Kesavan, R. Tiruvalam, M. H. Ab Rahim, M. I. bin Saiman, D. I. Enache, R. L. Jenkins, N. Dimitratos, J. A. Lopez-Sanchez, S. H. Taylor, D. W. Knight, C. J. Kiely and G. J. Hutchings, Science, 2011, 331, 6014, 195-199.

[24] T. A. G. Silva, R. Landers and L. M. Rossi, Catal. Sci. Technol., 2013, 3, 2993-2999.

[25] T. A. G. Silva, E. Teixeira-Neto, N. López and L. M. Rossi, Sci. Rep. 2015, 4.

[26] P. Landon, P. J. Collier, A. J. Papworth, C. J. Kiely and G. J. Hutchings, Chem. Commun., 2002, 0, 2058-2059.

[27] M. Chen, D. Kumar, C-W. Yi and D. W. Goodman, Science, 2005, 310, 291-293.

[28] E. K. Gibson, A. M. Beale, C. R. A. Catlow, A. Chutia, D. Gianolio, A. Gould, A. Kroner, K. M. H. Mohammed, M. Perdjon, S. M. Rogers and P. P. Wells, Chem. Mater., 2015, 27, 3714-3720.

[29] J. Xu, T, White, P. Li, C. He, J. Yu, W. Yuan and Y-F. Han, J. Am. Chem. Soc., 2010, 132, 10398-10406.

[30] D. I. Enache, R. L. Jenkins, N. Dimitratos, J. A. Lopez-Sanchez, S. H. Taylor, D. W. Knight, C. J. Kiely and G. J. Hutchings, Science, 2011, 331, 6014, 195-199.

[31] L. Prati, M. Rossi J. Catal. 1998, 176, 552-560.

[32] A. Abad, P. Concepcion, A. Corma, H. Garcla Angew Chem Int Ed 2005, 44, 4066-4069.

[33] J. Pritchard, L. Kesavan, M. Piccinini, Q. He, R. Tiruvalam, N. Dimitratos, J. A. Lopez-Sanchez, A. F. Carley, J. K. Edwards, C. J. Kiely and G. J. Hutchings, Langmuir, 2010, 26, 16568-16577.

[34] J. Pritchard, M. Piccinini, R. Tiruvalam, Q. He, N. Dimitratos, J. A. Lopez-Sanchez, D. J. Morgan, A. F. Carley, J. K. Edwards, C. J. Kielyb and G. J. Hutchings, Catal. Sci. Technol., 2013, 3, 308-317.

[35] Y. Li, J. Hu, D. Ma, Y. Zheng, M. Chen, H. Wan ACS Catal. 2018, 8, 1790-1795.

[36] B-J. Hwang, L. S. Sarma, J-M. Chen, C-H. Chen, S-C. Shih, G-R. Wang, D-G. Liu, J-F. Lee and M-T. Tang, J. Am. Chem. Soc., 2005 127, 11140-11145.

[37] A. R. Denton and N. W. Ashcroft, Phys. Rev. A, 1991, 43, 3161-3164.

[38] J. Kaiser, L. Leppert, H. Welz, F. Polzer, S. Wunder, N. Wanderka, M. Albrecht, T. Lunkenbein, J. Breu, S. Kümmel, Y. Lu and M. Ballauff, Chem. Chem. Phys., 2012, 14, 6487-6495.

[39] A. F. Lee, S. F. J. Hackett, J. S. J. Hargreaves and Karen Wilson, Green Chem., 2006, 8, 549-555.

[40] A. F. Lee and K. Wilson, Green Chem., 2004, 6, 37-42.

[41] J. H. Scofield, J. Electron Spectrosc., 1976, 8, 129-137.

[42] B. Ravel and M. Newville, J. Synch. Radiat., 2005, 12, 537-541. 
Entry for the Table of Contents (Please choose one layout)

Layout 1:

\section{FULL PAPER}

Dealloying and segregation of $\mathrm{PdO}$ by thermal treatment in air, confirmed by XRD, EXAFS and XPS, was found to be a better catalysts than AuPd (1:4) alloyed NPs for the oxidation of benzyl alcohol, which suggest a contribution of $\mathrm{PdO}$ phase that was not correlated before to an increase of activity in AuPd catalysts

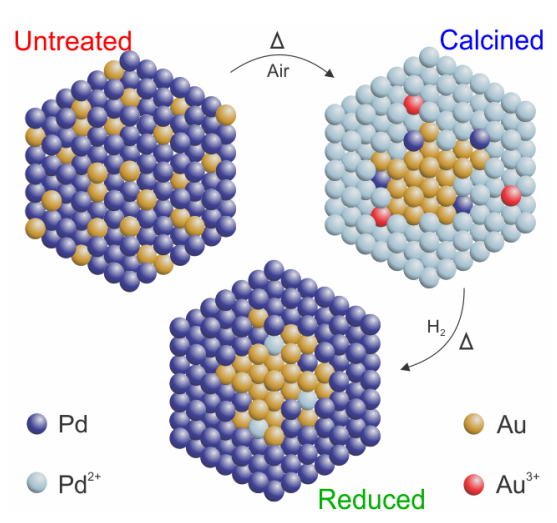

Tiago A. G. Silva, Camila P. Ferraz, Renato V. Gonçalves, Erico TeixeiraNeto, Robert Wojcieszak, Liane M. Rossi*

Page No. - Page No.

Restructuring of gold-palladium alloyed nanoparticles: a step towards more active catalysts for oxidation of alcohols 